\title{
ELECTRODEPOSITION OF COBALT NANOCLUSTERS FROM AMMONICAL CHLORIDE SOLUTIONS ONTO HOPG ELECTRODES. A KINETICAL AND MORPHOLOGICAL STUDY
}

\author{
L.H. MENDOZA HUIZAR ${ }^{\prime *}$, C.H. RIOS-REYES ${ }^{1}$, M.RIVERA ${ }^{2}$ \\ ${ }^{\prime}$ Area Académica de Química, Universidad Autónoma del Estado de Hidalgo, Carretera Pachuca-Tulancingo km. 4.5, 42186 \\ Mineral de la Reforma, Hidalgo, México. \\ ${ }^{2}$ Universidad Nacional Autónoma de México, Instituto de Física, Dpto. Materia Condensada, Ciudad Universitaria,
}

Coyoacán, C.P. 04510 México, D.F., México.

\begin{abstract}
A kinetical study about the Co electrodeposition onto Highly Oriented Pyrolytic Graphite electrodes from an aqueous solution containing $0.01 \mathrm{M} \mathrm{CoCl}+1$ $\mathrm{M} \mathrm{NH}_{4} \mathrm{CI}(\mathrm{pH}=7)$ was conducted at overpotential conditions through potentiostatic studies. The entire chronoamperograms were adequately predicted, considering the contribution to the total current of three different processes: a Langmuir-type adsorption process, a three-dimensional nucleation and growth and a proton reduction process. In all cases, the nucleation rate and the number of active nucleation sites are potential dependent. The Atomic Force Microscopy study revealed the presence of homogeneous cobalt clusters of less of $100 \mathrm{~nm}$ in height and $50 \mathrm{~nm}$ in diameter at different potential values.
\end{abstract}

Keywords: cobalt; nanoclusters; HOPG; kinetics; AFM; MFM.

\section{INTRODUCTION}

Materials based on cobalt have attracted a considerable attention due to their magnetic properties, which can be used in the production of sensors, heterogeneous catalysts, intercalation compounds for energy storage, magnetooptic recording media, among others. ${ }^{1-8}$ Specifically, the magnetic properties of isolated cobalt particles change considerably as their sizes enter the nanometer range because they exhibit a large magnetic coercivity, which may be employed to fabricate high density magnetic memory devices. ${ }^{9-15}$ Thus, it is not so strange that different methodologies are being developed to produce magnetic cobalt nanoclusters with controlled size and morphology. ${ }^{16-21}$ Probably, high vacuum methods, ${ }^{22}$ and thermal decomposition ${ }^{23}$ have been the preferred techniques to prepare monodisperse magnetic cobalt clusters onto different substrates. But, recently, electrodeposition is being recognized as an useful technique to produce cobalt nanoparticles. Also, it is important to highlight that electrodeposition is a simple electrochemical technique, which can be implemented at room temperature under ambient conditions. Moreover, these features make electrodeposition a non-expensive technique easily scalable to the industrial level. However, a good knowledge of the kinetic parameters involved during the electrodeposition process is required to achieve a precise control of the cobalt nanoclusters synthesis. In this sense, sulfate solutions have been the preferred systems to electrodeposit cobalt nanoclusters, ${ }^{24-30}$ onto stainless steel, ${ }^{24}$ thin niobium films, ${ }^{25}$ aluminium ${ }^{26}$ graphene, ${ }^{27}$ copper ${ }^{28}$ and Highly Oriented Pyrolytic Graphite (HOPG) electrodes. ${ }^{29,30}$ Although chloride solutions are widely employed for studying the cobalt electrochemistry, these plating baths have been scarcely used to electrodeposit cobalt nanoclusters. Probably, it is because chloride ions induces stress on the cobalt deposited, ${ }^{31}$ and may interact strongly with Co adatoms yielding drastic changes on the deposit morphology. ${ }^{32}$ Nevertheless, chloride electrolytes allow to get a higher electrical conductivity in the electrolyte, lower overpotential for cobalt deposition, and higher cathodic current efficiency. ${ }^{31}$. These features of chloride plating baths might diminish the cost related to the synthesis of cobalt nanoclusters by electrodeposition. To the best of our knowledge, there is no information regarding the nucleation kinetics of the cobalt nanoclusters onto HOPG from chloride solutions. We consider that a good understanding of the kinetics of cobalt electrodeposition will provide a good control of size and morphology of cobalt nanoparticles. Thus, in the present paper, a study of the cobalt electrodeposition onto HOPG electrode from chloride solutions is carried out by electrochemical, Atomic Force Microscopy (AFM) and Magnetic Force Microscopy (MFM) characterization techniques, in order to gain a deeper insight into this process.

\section{METHODOLOGY}

Cobalt was electrodeposited onto HOPG from a plating bath containing $0.01 \mathrm{M} \mathrm{CoCl}_{2}+1 \mathrm{M} \mathrm{NH} \mathrm{Cl}$ at $\mathrm{pH}=7$. Under these conditions, the main chemical species of $\mathrm{Co}(\mathrm{II})$ ion is the $\left[\mathrm{Co}\left(\mathrm{H}_{2} \mathrm{O}\right)_{6}\right]^{2+}$ complex with an equilibrium potential of $-0.533 \mathrm{vs} \mathrm{Ag} / \mathrm{AgCl}(\mathrm{KCl}$ sat $){ }^{33} \mathrm{All}$ plating baths used in the present work were prepared using analytic grade reagents and ultra pure water (Millipore-Q system) and were deoxygenated by bubbling $\mathrm{N}_{2}$ for 15 minutes before each experiment. The electrode structure can also induce changes in the deposits, modifying its electrodeposition energy, its size, shape and affecting the electrodeposition process kinetics. Probably, carbon electrodes are the preferred substrates to study the cobalt electrodeposition process, because they offer an inert surface in where it is possible to study the nucleation and growth process neglecting the metal-metal interaction. In order to analyze exclusively the cobalt electrodeposition process, it was selected the HOPG electrode. This substrate exhibits semi-metallic characteristics that decrease the Metal-Substrate interaction during the nucleation and growth process. ${ }^{34}$ Moreover, HOPG electrode has less structural defects in comparison to other polycrystalline carbon electrodes. Freshly cleaved HOPG surfaces were employed in each experiment to guarantee the existence of extended terraces with hcp $(0001)$ orientation. A graphite bar was used as counter electrode while an $\mathrm{Ag} / \mathrm{AgCl}$ electrode (in saturated $\mathrm{KCl}$ ), was used as a reference electrode. All experiments were carried out at room conditions in unstirred solutions. The electrochemical experiments were carried out in an EPSILON potentiostat with the BASi-EpsilonEC software. Cyclic voltammetry was carried out in the $0.600 \mathrm{~V}$ to $-1.200 \mathrm{~V}$ potential range. The kinetics of nucleation of cobalt deposits were studied through the analysis of the experimental current density transients obtained with the single potential step technique. The analysis of the morphology and magnetic properties of the electrodeposits was carried outthrough AFM and MFM images, which were obtained with a JEOL JSPM 4210 microscope in the lift mode.

\section{RESULTS AND DISCUSSION}

3.1 Voltammetric study

Figure 1 depicts a typical cyclic voltammogram obtained from the $\mathrm{HOPG} / 0.01 \mathrm{M} \mathrm{CoCl}_{2}+1 \mathrm{M} \mathrm{NH}_{4} \mathrm{Cl}$ system at the scan rate of $20 \mathrm{mV} \mathrm{s}^{-1}$. Note at direct scan, the presence of three slopes. The slope II and III are associated with the presence of electrochemical processes on the electrode surface (see close up in Figure 1a). The slope I is the zone of null current where not electrochemical processes are recorded, while the peak $\mathrm{A}$ is related to the cobalt reduction process. In the anodic zone, two current density peaks B (shoulder) and C appeared at the potentials of $-0.450 \mathrm{~V}$ and $-0.250 \mathrm{~V}$ respectively. These anodic peaks have been associated with either the dissolution of cobalt previously electrodeposited at direct scan, ${ }^{33}$ or the dissolution of hydrated cobalt oxide layers. ${ }^{35}$ In order to investigate if the cathodic current recorded in zone II corresponds to cobalt electrodeposited, a linear voltammetry on the HOPG/1 $\mathrm{M} \mathrm{NH}_{4} \mathrm{Cl}$ system was recorded at the potential range 0.600 to $-1.200 \mathrm{~V}$. Figure 2 shows a comparison of the experimental voltammograms obtained from the solutions with and without $\mathrm{Co}^{2+}$ ions. From this comparison, it is clear that only the current recorded in zone III corresponds to the cobalt electrodeposition. Therefore, the cobalt electrodeposition in the present system is beginning at potential values lower than $-1.000 \mathrm{~V}$. 


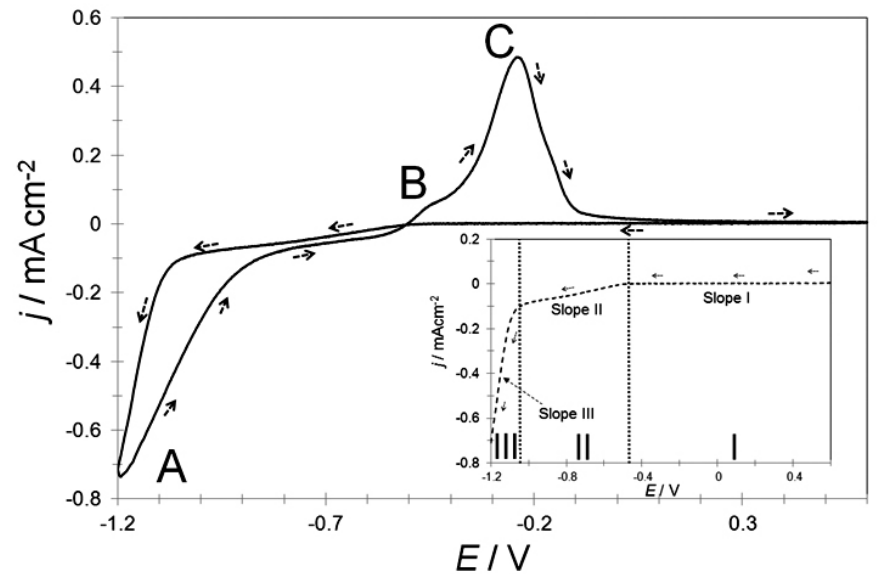

Fig. 1. A typical cyclic voltammogram obtained at $20 \mathrm{mV} \mathrm{s}^{-1}$ from the system $\mathrm{HOPG} / 0.01 \mathrm{M} \mathrm{CoCl}_{2}+1 \mathrm{M} \mathrm{NH}_{4} \mathrm{Cl}$ at $\mathrm{pH}=7$. The potential scan was started at $0.600 \mathrm{~V}$ toward the negative direction. Arrows indicate the potential scan direction. Cathodic current density peak (A) and anodic peaks (B (shoulder) and C) are also indicated in the Figure.

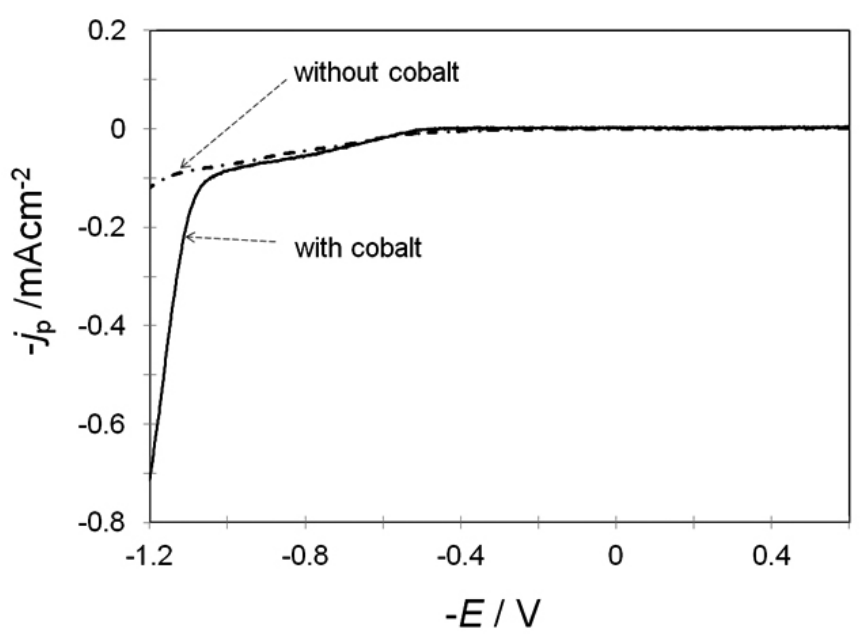

Fig. 2. A typical lineal voltammogram obtained at $20 \mathrm{mV} \mathrm{s}^{-1}$ from the system HOPG/ $0.01 \mathrm{M} \mathrm{CoCl}_{2}+1 \mathrm{M} \mathrm{NH}_{4} \mathrm{Cl}$ at $\mathrm{pH}=7$ ( solid line) and $\mathrm{HOPG} /$ $1 \mathrm{M} \mathrm{NH}_{4} \mathrm{Cl}$ at $\mathrm{pH}=7$ (broken line). The potential scan was started at $0.600 \mathrm{~V}$ toward the negative direction.

3.2 Kinetic analysis of the 3D nucleation and growth process

Figure 3 shows characteristic current density transients obtained at overpotential conditions $(E \leq-0.533 \mathrm{~V}$ vs $\mathrm{Ag} / \mathrm{AgCl})$ from the HOPG/ 0.01 $\mathrm{M} \mathrm{CoCl}_{2}+1 \mathrm{M} \mathrm{NH}_{4} \mathrm{Cl}$ system. Observe, that all these transients exhibit a falling current at shorter times, also the $j$ vs $t$ plot shows a maximum and then approaches to the limiting diffusion current. We plotted the current density, which falls after the maximum vs $1 / t^{1 / 2}$ and it was obtained a linear relationship. This result suggests that the electrodeposition process of cobalt, in the present system, is controlled by diffusion. ${ }^{36}$

In the literature it has been reported that the cobalt electrodeposition begins through progressive nucleation, which may change to instantaneous nucleation when the cobalt concentration is increased. ${ }^{37}$ Also, the cobalt electrodeposition may occur through a nucleation process under a charge transfer. ${ }^{37}$ In order to identify the type of nucleation and growth process of the system analyzed in the present work, we followed the methodology reported by Scharifker et al., to identify the type of nucleation and growth mechanism as progressive or instantaneous comparing the nondimensional experimental transients with their respective dimensionless plots. ${ }^{38}$ These curves are plotted substituting the coordinate values of the experimental local maximum $\left(t_{\mathrm{m}}, j_{\mathrm{m}}\right)$, in: ${ }^{38}$

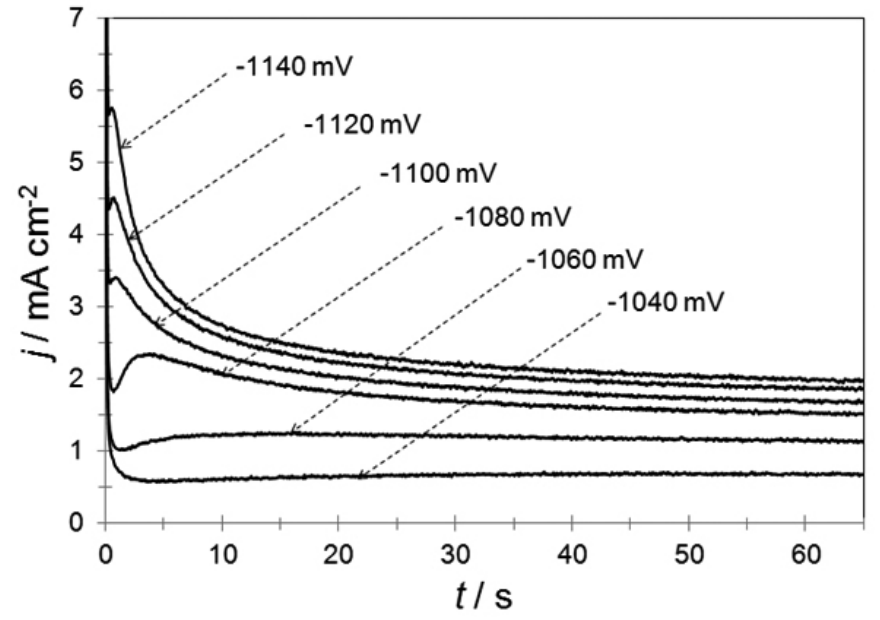

Fig. 3. Current transients obtained by means of the potential step technique for different potential step values $(\mathrm{mV})$ indicated in the Figure. In all the cases, the initial potential was $0.600 \mathrm{~V}$ vs $\mathrm{Ag} / \mathrm{AgCl}$.

$$
\frac{j^{2}}{j_{m}^{2}}=\frac{1.9542}{t / t_{m}}\left\{1-\exp \left[-1.2564\left(\frac{t}{t_{m}}\right)\right]\right\}^{2}
$$

for instantaneous nucleation and in

$$
\frac{j^{2}}{j_{m}^{2}}=\frac{1.2254}{t / t_{m}}\left\{1-\exp \left[-2.3367\left(\frac{t}{t_{m}}\right)^{2}\right]\right\}^{2}
$$

for progressive nucleation.

A comparison of an experimental transient with the theoretical dimensionless curves derived through equations (1) and (2) is shown in Figure 4. It is clear that at $t / t_{m}<1$ the experimental curve compare favorably with the instantaneous behavior. At $t / t_{m}>1$, the experimental curve could not be classified as either progressive or instantaneous. Here, it must be reminded that the theoretical curves generated by Eqs. (1) and (2) correspond to two extreme cases of the nucleation process and in some cases a classification is not possible. ${ }^{39}$ Moreover, these kinds of plots have been strongly criticized in the literature. ${ }^{39}$ However, it has been reported that an additional efficacy of these plots is that if the experimental data fall within the range of validity of the theory proposed the full equation can be used to predict the overal behavior. Additionally, these plots can be used to identify the presence of an additional process to the nucleation and growth process. ${ }^{40}$ Thus, the deviation of the current observed at $t / t>1$, indicates the presence of additional electrochemical processes, which are contributing to the total current. For the cobalt electrodeposition case, this additional contribution has been identified as a proton reduction process. ${ }^{40}$ Therefore a classification as instantaneous or progressive process is not definitive from the observed in Figure 4.

Thus, considering the above mentioned, the density current transients depicted in Figure 3, should be explained by the following equation.

$$
j(t)=j_{\mathrm{a}-\mathrm{d}}(t)+j_{3 D-P R}(t)
$$

where $\left.j_{\text {ad }}(t)\right)$ is the current density for a Langmuir-type adsorptiondesorption process given by: ${ }^{41}$

$$
j_{\mathrm{a}-\mathrm{d}}(t)=k_{1} \exp \left(-k_{2} t\right),
$$

while $j_{3 D-R}(t)$ is the current associated with the cobalt nucleation and growth process, $j_{3 D}(t)$, involving a proton reduction process, $j_{R}(t):^{: 42}$ 


$$
j_{\mathrm{a}-\mathrm{d}}(t)=k_{1} \exp \left(-k_{2} t\right)
$$

where

$$
\begin{aligned}
& P_{1}=z_{P R} F k_{P R}\left(\frac{2 c M}{\pi \rho}\right)^{1 / 2} \\
& P_{2}=N_{0} \pi\left(\frac{8 \pi c}{\rho}\right)^{1 / 2} D \\
& P_{3}=A \\
& P_{4}=\frac{2 F D^{1 / 2} c}{\pi^{1 / 2}}
\end{aligned}
$$

$\mathrm{Z}_{\mathrm{PR}}$ is the number of electrons transferred during the proton reduction reaction, while $k_{\mathrm{PR}}$ corresponds to the rate constant of the proton reduction process. The nucleation rate, the number of active nucleation sites and the diffusion coefficent are represented as $A, N_{0}$ and $D$, respectively. All the other parameters used in equations (4) to (8) have their electrochemical conventional meanings. The evaluation of the kinetic parameters associated with the transients depicted in Figure 3, we carried out through a non-linear fitting of the experimental data to equation (3). Figure 5 shows a comparison of an experimental current transient obtained at $-1.080 \mathrm{~V}$ with the theoretical current transient generated by Eq. (3). Note that the proposed model describes adequately the experimental current transient behavior.

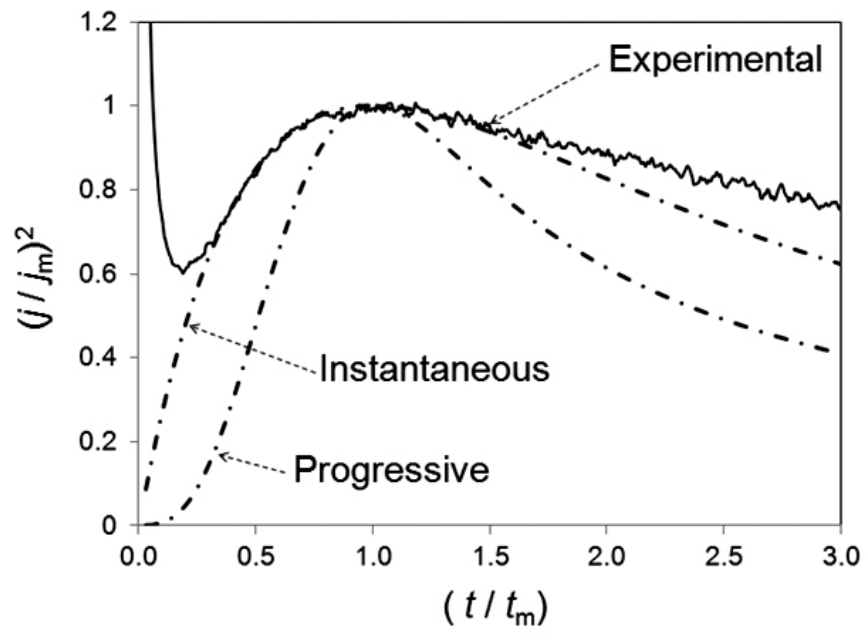

Fig. 4. Comparison of an experimental current transient obtained at $-1.080 \mathrm{~V}$ and their theoretical non-dimensional curves corresponding to a 3D instantaneous nucleation (equation 1) and 3D progressive nucleation (equation 2).

The kinetic parameters obtained in the present work are reported in Table 1. The average diffusion coefficient value is $7 \times 10^{-5} \mathrm{~cm}^{2} \mathrm{~s}^{-1}$, see Table 1 . Note that the coefficient value obtained in the present work is larger than the reported for electrolytic solutions containing ammoniacal sulfate $\left(2.65 \times 10^{-6} \mathrm{~cm}^{2} \mathrm{~s}^{-1}\right){ }^{43}$ sodium sulfate $\left(0.9 \times 10^{-5} \mathrm{~cm}^{2} \mathrm{~s}^{-1}\right),{ }^{40}$ citrate $\left(2.0 \times 10^{-5} \mathrm{~cm}^{2} \mathrm{~s}^{-1}\right)^{44}$, aqueous chloride $\left(0.5 \times 10^{-5} \mathrm{~cm}^{2} \mathrm{~s}^{-1}\right),{ }^{45}$ or acid ammoniacal $\left(1.3 \times 10^{-5} \mathrm{~cm}^{2} \mathrm{~s}^{-1}\right)^{46}$ solutions. Even though, similar cobalt concentrations were employed in such electrolytic baths, the $\mathrm{pH}$ value of these electrolytic media is acid. In this sense, it is important to mention that the dissociation of the media will tend to reduce the overall mobility of the solute component. ${ }^{47}$ Thus, at acid $\mathrm{pH}$ values a lower diffusion coefficient is expected in comparison with neutral electrolytic baths. On the other hand, the $A$ and $N_{0}$ values increase as the applied potential becomes more negative. The nucleation rates obtained in the present work are similar to those obtained onto HOPG substrates from sulfate systems. ${ }^{40,34}$ On the other hand, the number of active nucleation sites is larger that the obtained from sulfate systems onto HOPG electrodes. ${ }^{40,34}$ Also, it can be observed an increment in $k_{\mathrm{PR}}$ values at lower applied potentials, which indicates that the reduction proton process is favored at bigger overpotentials. The $k_{\mathrm{PR}}$ values in the present work are lower that the obtained from acid sulfate solutions which suggest a less competition by $\mathrm{H}^{+}$ions with the $\mathrm{Co}^{2+}$ ions by the active sites on the electrode surface, under neutral $\mathrm{pH}$ values.

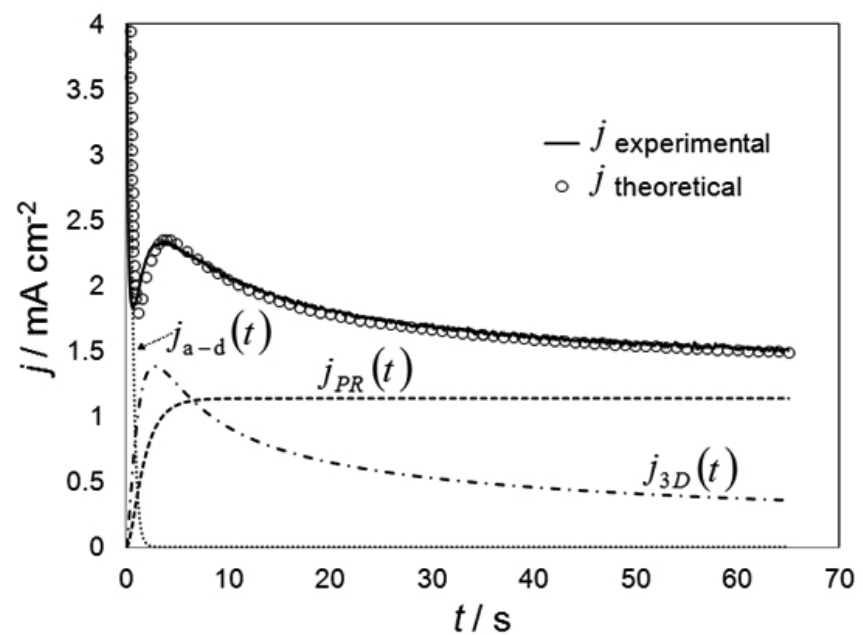

Fig. 5. Comparison of an experimental current density transient (-) recorded during the Co electrodeposition process at $-1.080 \mathrm{~V}$ and a theoretical transient ( $\mathrm{o} o \mathrm{o}$ ) obtained by nonlinear fitting of Eq. (3) to the experimental data. The contribution to the total current of the adsorption, 3D nucleation and growth and a proton reduction processes are indicated in the Figure.

Table 1. Potential dependence for the nucleation parameters during Co electrodeposition onto HOPG electrodes from an aqueous solution containing $0.01 \mathrm{M} \mathrm{CoCl}_{2}+1 \mathrm{M} \mathrm{NH}_{4} \mathrm{Cl}$ at $\mathrm{pH}=7$. The values were obtained from best-fit parameters found through the fitting process of the experimental $j$ - $t$ plots using Equation (3).

\begin{tabular}{|c|c|c|c|}
\hline$E / \mathrm{V}$ & $A / \mathrm{s}^{-1} \mathrm{~cm}^{-2}$ & $N \mathrm{X} 10^{-8} \mathrm{~cm}^{2}$ & $\begin{array}{c}k_{\mathrm{PR}} \mathrm{X} 10^{-8} \mathrm{~mol} \\
\mathrm{~cm}^{-2} \mathrm{~s}^{-1}\end{array}$ \\
\hline-1.04 & 0.05 & 3.52 & 0.37 \\
\hline-1.06 & 0.12 & 4.03 & 0.74 \\
\hline-1.08 & 0.70 & 9.31 & 1.17 \\
\hline-1.1 & 1.80 & 15.60 & 1.34 \\
\hline-1.12 & 2.20 & 21.64 & 1.34 \\
\hline-1.14 & 4.30 & 27.18 & 1.67 \\
\hline
\end{tabular}

3.3 Analysis of the kinetic parameters

A distinctive feature of electrochemical nucleation and growth is the size of a critical nucleus, a nucleus that has a $50 \%$ chance of becoming a stable entity, rather than dissolving back into the electrolyte or becoming a part of nuclei growing in different places on the electrode surface ${ }^{48,49}$ From the nucleation rate values reported in Table 1, it is possible to calculate the number of atoms that form this critical nucleus by employing the following equation: ${ }^{48,49}$

$$
n_{\mathrm{c}}=\frac{k_{\mathrm{B}} T}{z e_{0}} \frac{\mathrm{d} \ln A}{\mathrm{~d} \eta}-\alpha
$$

In the last equation $k_{\mathrm{B}}, T, z$, and $e_{0}$ are the Boltzmann constant, the absolute temperature, the number of transferred electrons and the elementary electric charge, respectively. The value of the slope $\operatorname{dln} A(\mathrm{M} 1) / \mathrm{d} \eta \approx 45.6$ was obtained from the linear experimental dependence of $\ln A$ vs $\eta$ (see Figure 6). If one substitutes $\alpha=0.5$ and the value of the slope $\operatorname{dln} A(\mathrm{M} 1) / \mathrm{d} \eta$ in Eq. (9) the result is $n_{\mathrm{c}}=0$. This value means that each active site on the HOPG electrode surface acts as a critical nucleus. ${ }^{49,50}$ 


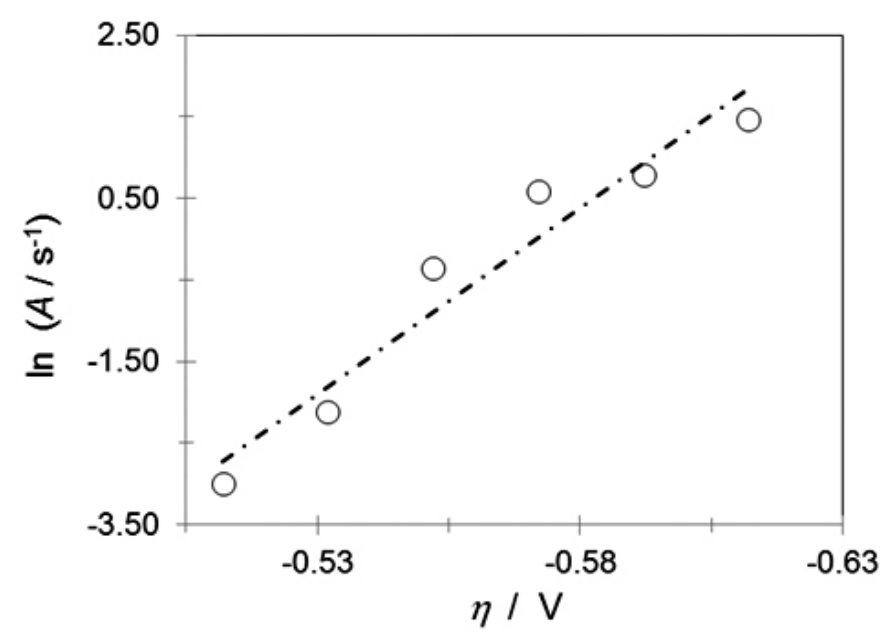

Fig. 6. In $A$ vs $\eta$ plot, used to calculate the critical size of Co nucleus according to Eq. (9). The broken straight line corresponds to the linear fit of the experimental data.

On the other hand, the $k_{\mathbb{R}}$ values were analyzed by using the well known Buttler-Volmer equation,

$$
k_{P R}=k_{P R}^{0} \exp \left[\frac{-\alpha_{P R} z F E}{R T}\right]
$$

Note that this equation can be linearized if we take the natural logarithm of both sides of the equation. Then, from the slope of the $\ln k_{R}$ vs E plot, it is possible to calculate the value of $\alpha_{\mathbb{R}}$ as 0.35 . This value compares very well with the calculated for glassy carbon electrodes. ${ }^{42}$

On the other hand, in a diffusion controlled nucleation and growth process, the growing nuclei is able to inhibits the nucleation process, because the diffusion fields associated with already existing growing nuclei, and their overlapping of these zones, may interrupt the nucleation and thus lead to a saturation nucleus density $\left(N_{\mathrm{S}}\right)$. Thus, it is possible to calculate the efficiency of the use of the HOPG surface available nucleation sites as $N_{\mathrm{S}} / N_{0}$, where $N_{\mathrm{S}}$ is the saturation number of nuclei. $N_{\mathrm{S}}$ can be calculated through the equation (11), ${ }^{52}$

$$
N_{\mathrm{S}}=\left(\frac{A N_{0}}{2 k^{\prime} D}\right)^{1 / 2}
$$

where

$$
k^{\prime}=\frac{4}{3}\left(\frac{8 \pi \mathrm{c}_{\mathrm{o}} M}{\rho}\right)^{1 / 2}
$$

In Table 2 are reported the $N_{\mathrm{S}}$ and $N_{\mathrm{S}} / N_{0}$ values obtained in the present work. Note that these values increase with the applied potential. Also, it is interesting to observe that the values of the $N_{\mathrm{S}} / N_{0}$ are low, which may be caused by the occupation of the active sites of the HOPG electrode surface by $\mathrm{NH}_{4}^{+}$and $\mathrm{H}^{+}$ions. ${ }^{29}$ However, these adsorbed ions may stop the diffusion of Co ad-atoms towards the growing nuclei, which may induce the growth of small clusters on the electrode surface. ${ }^{29}$ Moreover the ratio $N_{\mathrm{S}} / N_{0}$ is lower than the reported for glassy carbon electrodes (GCE). Probably this is due to the existence of less structural defects on HOPG electrodes, in comparison with GCE electrodes.
Table 2. Potential dependence of the $N_{\mathrm{S}}$ and $N_{\mathrm{S}} / N_{0}$ values from an aqueous solution containing $0.01 \mathrm{M} \mathrm{CoCl}_{2}+1 \mathrm{M} \mathrm{NH}_{4} \mathrm{Cl}$ at $\mathrm{pH}=7$ calculated from physical constants reported in Table 1 and Equation (11).

\begin{tabular}{|c|c|c|}
\hline$E / \mathrm{V}$ & $N_{\mathrm{S}} \times \mathbf{1 0}^{-6} \mathrm{~cm}^{2}$ & $\left(N_{\mathrm{S}} / N_{0}\right) \times \mathbf{1 0}$ \\
\hline-1.04 & 0.03 & 0.76 \\
\hline-1.06 & 0.04 & 1.11 \\
\hline-1.08 & 0.16 & 1.76 \\
\hline-1.1 & 0.34 & 2.17 \\
\hline-1.12 & 0.44 & 2.04 \\
\hline-1.14 & 0.69 & 2.55 \\
\hline
\end{tabular}

3.4 Morphological study

AFM images of cobalt electrodeposited on HOPG electrode at -1.040 , -1.080 and $-1.100 \mathrm{~V}$ are epicted in Figure 7 . Figure $7 \mathrm{a}$, show the AFM image obtained at $-1.040 \mathrm{~V}$, in this image it is possible to observe the formation of small clusters of 50-100 nm in diameter and 80-100 nm in height. Similar results were obtained at $-1.080 \mathrm{~V}$, see Figure $7 \mathrm{~b}$. Observe that the cobalt clusters obtained at $-1.100 \mathrm{~V}$ are bigger than those obtained at -1.040 and $-1.080 \mathrm{~V}$, see Figure $7 \mathrm{c}$. This is due to the overlapping of small cobalt clusters of $50 \mathrm{~nm}$ in diameter approximately. Also, it is interesting to observe that the bigger cobalt clusters have similar height and width at the different applied potentials. Thus, in the present system to apply lower potentials increase the number of nuclei on the electrode surface, but not modify substantially their maximum size. However it is clear the formation of cobalt cluster with different size, which may be indicative of a progressive nucleation process.

a)
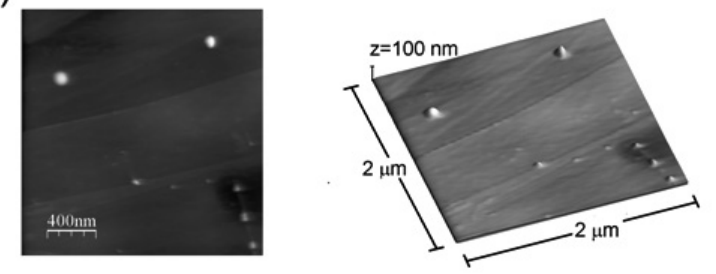

b)
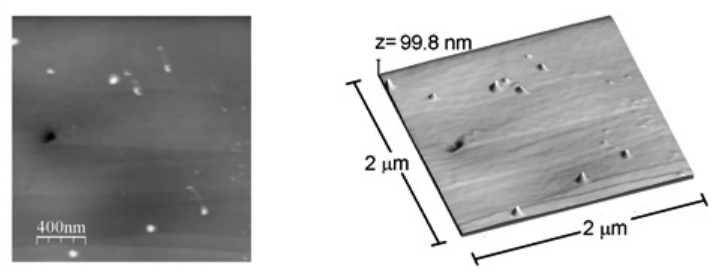

c)
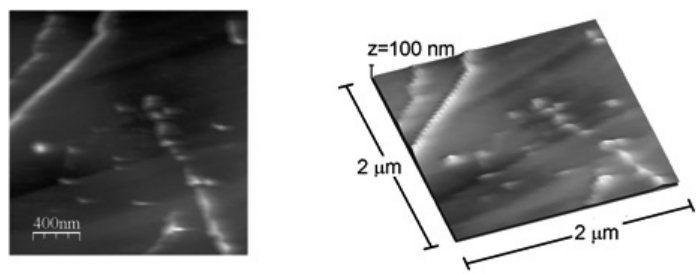

Fig. 7. AFM topographic images of the Co electrodeposition from the system HOPG/ $0.01 \mathrm{M} \mathrm{CoCl}_{2}+1 \mathrm{M} \mathrm{NH}_{4} \mathrm{Cl}$ at $\mathrm{pH}=7$ at a) $\left.-1.040 \mathrm{~V}, \mathrm{~b}\right)-1.080$ $\mathrm{V}$ and c) $-1.100 \mathrm{~V}$.

Figure 8 shows the magnetic images associated with Fig. 7. Fig. 8a corresponds to the magnetic images for clusters obtained at $-1.040 \mathrm{~V}$, observe the presence of disperse magnetic clusters, which can be directly related to the 
topographic features observed in Figure 7a. In this image, the color contrast within the overlapped nuclei suggests different magnetic domain regions. Since, bright colors correspond to repulsive interactions while the dark ones represent attractive interactions. A similar behavior is exhibited by the clusters shown in Figure 8 b. From Figure 8c, it is clear the formation of aggregates with a magnetic coupling between them.

a)

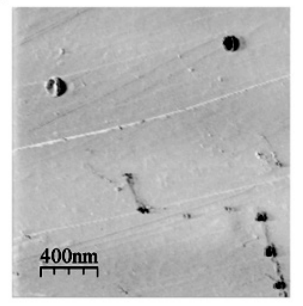

b)

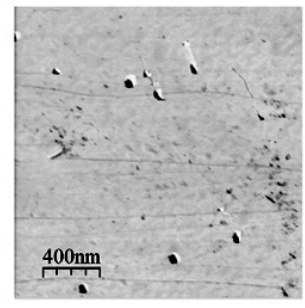

c)

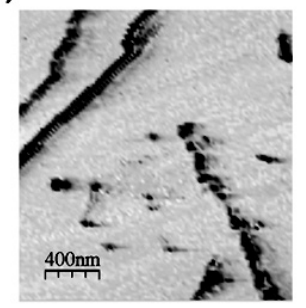

Fig. 8. MFM images of topographic images obtained at a) $-1.040 \mathrm{~V}, \mathrm{~b})-1.080 \mathrm{~V}$ and c) $-1.100 \mathrm{~V}$.

\section{CONCLUSIONS}

Co nanoclusters were electrodeposited onto HOPG electrodes from neutral amoniacal solutions. The results suggest that there is a competition by the available nucleation active sites between the proton reduction and the cobalt electrodeposition processes. The diffusion coefficient value obtained in the present work is bigger that the reported in the literature for acid electrolytic baths, where the cobalt concentration is similar. Probably, it is because at neutral solutions the mobility of the solute component is major in comparison with acid solutions. In all cases the nucleation and growth parameters such as $A$ and $N_{0}$ are potential dependent and their values are increased as the applied potential diminish. The AFM study revealed that the number of nuclei depend on the applied potential, but there is a maxim cluster's size of synthesized cluster under our experimental conditions. This maxim height is $100 \mathrm{~nm}$ in height and $50 \mathrm{~nm}$ in diameter at different applied potential values. This behavior may be explained in terms of adsorption of $\mathrm{NH}_{4}^{+}$and $\mathrm{H}^{+}$ions on the growing nuclei, which limit its size. However, additional studies are necessary to verify this result.

\section{ACKNOWLEDGMENTS}

LHMH expresses their gratitude to the Mexican National Council for Science and Technology (CONACYT) for financing this work through the Research Project Grant 257823 and to the Universidad Autónoma del Estado de Hidalgo. I.Q. Mario Monroy for AFM images and LCM at IFUNAM for the use of the microscopy facilities.

\section{REFERENCES}

1. M. Ando, T. Kobayashi, S. Iijima, M. Harita, J. Mater.Chem.7, 1779 (1997).

2. H. Yamaura, J. Tamaki, K. Moriya, N. Miura, N. Yamazoe, J. Electrochem. Soc. 144, L158 (1997).

3. P. Nkeng, J. Koening, J. Gautier, P. Chartier, G. Poillerat, J. Electroanal. Chem. 402, 81(1996).

4. S. Weichel, P.J. Møller, Surf. Sci. 399, 219 (1998).

5. Y. Okamoto, T. Imanaka, S. Teranishi, J. Catal. 65, 448 (1980).

6. K. Ramachandram, C.O. Oriakhi, M.M. Lerner, V.R. Koch, Mater. Res. Bull. 31, 767 (1996).

7. M.G. Hutchins, P.J. Wright, P.D. Grebenik, Sol. Energ. Mater.16, 113 (1987).

8. E. Barrera, I. Gonzales, T. Viveros, Sol. Energ. Mater. Sol. C.51, 69 (1998).

9. Y. Gauthier, P. Dolle, R. Boudoing-Savois, W. Hebestrein, E. Platzgummer, M. Schmid, P. Varga, Surf. Sci. 296, 137 (1998).

10. E. Lunggren, J. Alvarez, X. Torelles, K.F. Peters, H. Isern, S. Ferrer, Phys. Rev. B59, 2431 (1999).

11. E. Platzgummer, M. Sporn, R. Koller, M. Schmid, W. Hofer, P. Varga, Surf. Sci. 453, 214 (2000).

12. P. Varga, M. Schmid, Appl. Surf. Sci. 141, 287 (1999)

13. F.J. Aden-Broeder, W. Hoving, P.J.H. Bloemen, J. Magn. Magn. Mater.93, 562 (1991).
14. L. Smardz, B. Szymanski, R. Gontarz, P. Stefanski, J. Barnas, J. Magn Magn. Mater.120, 239 (1993).

15. K. Spörl, D. Weller, J. Magn. Magn. Mater.93, 379 (1991).

16. K. Morgenstern, J. Kibsgaard, J.P. Lauritsen, E. Laegsgaard, F. Besenbacher, Surf. Sci. 601, 1967 (2007).

17. E. Napetschnig, M. Schmid, P. Varga, Surf. Sci. 601, 3233, 2007.

18. J.S. Pan, R.S. Liu, Z. Zhang, S.W. Poon, W.J. Ong, E.S. Tok, Surf. Sci.600, 1308 (2006).

19. S.W. Poon, J.S. Pan, E.S. Tok, Phys. Chem. Chem.Phys.8, 3326 (2006).

20. S.A. Koch, R.H. Velde, G. Palasantzas, J.Th.M. De Hosson, Appl.Surf. Sci.226, 185 (2004).

21. F. Dumas-Bouchiat, H.S. Nagaraja, F. Rossignol, C. Champeaux, G. Trolliard, A. Catherinot, D.J. Givord, J. Appl. Phys. 100, 064304-1 (2006).

22. D. Lebedev, N. Nurgazizov, A. Chuklanov, A. Bukharaev, Adv. Nanoparticles 2, 236 (2013).

23. H. T. Yang, Y. K. Su, C. M. Shen, T. Z. Yang, H. J. Gao. Surf. Interface Anal. 36, 155 (2004).

24. N.A. Resali, App. Mech. Mater. 393, 140 (2013).

25. H-Y. Ho, S.-J. Chen, W.-Y. Lin, Y. Liou, H.-W Cheng, IEEE T. Magn. 48, 3940 (2012).

26. P. G. Schiavi, P. Altimari, F. Pagnanelli, E. Moscardini, L. Toro, Chem. Eng. Trans. 43, 673 (2015).

27. Y. Song, Z. He, H. Zhu, H. Hou, L. Wang, Electrochim. Acta 58, 757 (2011).

28. F. Pagnanelli, P. Altimari, M. Bellagamba, G. Granata, E. Moscardini, P. G. Schiavi, L.Toro, Electrochim. Acta 155, 228 (2015).

29. M. Rivera, C.H. Rios-Reyes, L.H. Mendoza-Huizar, Appl. Surf. Sci. 255, 1754 (2008).

30. M. Rivera, C.H. Rios-Reyes, L.H. Mendoza-Huizar, J. Magn. Magn. Mater. 323, 997 (2011).

31. O. E. Kongstein, G. M. Haarberg, J. Thonstad, J. Appl. Electrochem. 37, 669 (2007).

32. Y. Kuo, W. Liao, S.L. Yau, Langmuir, 30, 13890 (2014).

33. M. Palomar-Pardave, I. González, A.B. Soto, E.M. Arce, J. Electroanal. Chem. 443, 125 (1998).

34. L.H. Mendoza-Huizar, C.H. Rios-Reyes; M. Rivera, Quím. Nova 33(5), 1109 2010]

35. D. Grujicic, B. Pesic, Electrochim. Acta, 49, 4719 (2004).

36. F. G. Cottrell, Z. Phys. Chem. 42,385 (1902).

37. N. Myung, K.H. Ryu, P.T.A. Sumodjo, K. Nobe, Electrochemical Society Proceedings, PV 97-27, p. 136.

38. B. Scharifker, G. Hills, Electrochim. Acta 28, 879 (1983).

39. L. Heerman, A. Tarallo. Electrochem Commun. 2, 85 (2000).

40. C.H. Rios-Reyes,L.H. Mendoza-Huizar, M. Rivera, J. Solid State Electr. 14, 659 (2010)

41. H. Holzle, U. Retter, D.M. Kolb, J. Electroanal. Chem.371, 101 (1994).

42. M. Palomar-Pardave, B.R. Scharifker, E.M. Arce, M. Romero-Romo, Electrochim. Acta 50, 4736 (2005).

43. C.H. Rios-Reyes, M. Granados-Neri, L.H. Mendoza-Huizar, Quím. Nova 32(9) 2382 (2009).

44. A.C. Frank, P.T.A. Sumodjo, Electrochim. Acta 132, 75 (2014)

45. C. Q. Cui, S.P. Jiang, A.C.C. Tseung, J. Electrochem. Soc. 137, 3418 (1990) 
46. M. Palomar-Pardavéa, B.R. Scharifker, E.M. Arce, M. Romero-Romo, Electrochim. Acta, 50(24) 4736 (2005).

47. D.G. Leaist, Can. J. Chem. 62, 1692 (1984)

48. A. Milchev, S. Stoyanov, R. Kaischev, Thin Solid Films 22, 255 (1974).

49. A. Milchev, Contemp. Physics 32, 321 (1991).
50. A. Milchev,"Electrocrystallization: Fundamentals of nucleation and growth, ch. 2.2.3," Kluwer Academic Publishers: Massachusetts, (2002).

51. M. Noel, K. Vasu, "Cyclic Voltammetry and the Frontiers of Electrochemistry (Chapter 7)", Aspect, London (1990).

52. 44. B.R. Scharifker, Acta Cient. Venez. 35, 211 (1984). 